\title{
Erratum
}

\section{Simultaneous utilization of heterotrophic substrates by Hansenula polymorpha MH30 results in enhanced growth rates}

\section{Uta Brinkmann and Wolfgang Babel}

Institut für Biotechnologie, Permoserstrasse 15, O-7050 Leipzig, Federal Republic of Germany

In: Appl Microbiol Biotechnol 37:98-103

Due to an unfortunate printing error on page 99 , table 1 was missing:

Table 1. Maximum specific growth rates of Hansenula polymorpha MH30 on several heterotrophic substrates (all at $5 \mathrm{~g} \cdot 1^{-1}$ ) and on mixtures of them estimated in carbon-limited chemostat culture

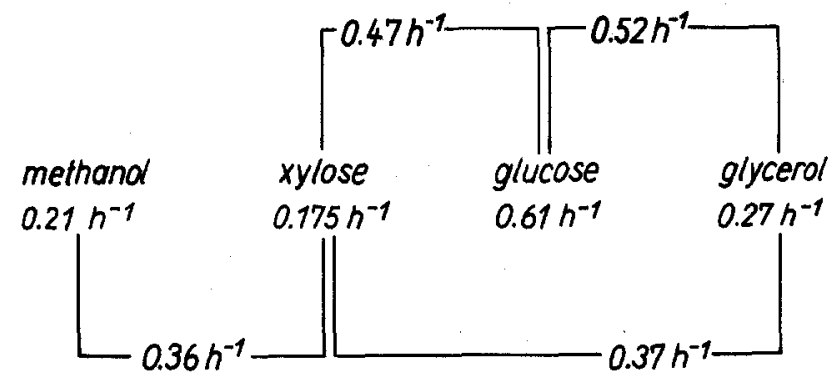

Mixture proportions: $125 \mathrm{mM}$ methanol / $43.3 \mathrm{mM}$ xylose; $54.3 \mathrm{~mm}$ glycerol / $33.3 \mathrm{~mm}$ xylose; $33.3 \mathrm{~mm}$ xylose / $28 \mathrm{mM}$ glucose; $54.3 \mathrm{~mm}$ glycerol / $6.95 \mathrm{mM}$ glucose 